\title{
Pode a beleza salvar o mundo? Estética, capitalismo e o encantamento do mundo
}

Wendell Marcel Alves da Costa

LIPOVETSKY, Gilles; SERROY, Jean.

A estetização do mundo: viver na era do capitalismo artista.

Trad. Eduardo Brandão. $1^{\circ} \mathrm{ed}$. São Paulo:

Companhia das Letras, 467p., 2015.

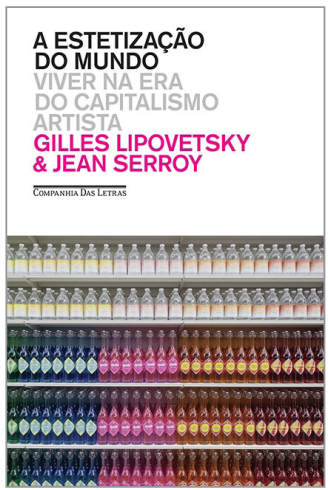

Resumo:Esta resenha destaca as principais características apresentadas na obra $A$ estetização do mundo. A ênfase aqui recai nos aspectos do capitalismo artista e em como esse fenômeno se configura na sociedade por meio de narrativas, representações e símbolos da cultura e das mídias contemporâneas.

Palavras-chave: estética; capitalismo artista; cultura.

Abstract: Can beauty save the world? Aesthetics, capitalism and enchantment of the world - This review highlights the main characteristics presented in the work The aesthetization of the world. The emphasis here is on aspects of artist capitalism and how this phenomenon is shaped in society through narratives, representations and symbols of contemporary culture and media.

Keywords:aesthetics; artist capitalism; culture. 
O livro A estetização do mundo procura desvendar como se organiza, estrutura e funciona o que os autores chamam de capitalismo artista, que se origina a partir do desenvolvimento de uma economia global fundada na premissa do consumo acelerado. O cerne desse conceito está em que nenhum sistema econômico ou cultural está à parte do que se intitula "economia transestética", porque todos os campos da economia e da vida cotidiana estão interligados na construção das relações de consumo e de produção do imaginário social sobre as coisas que fazem parte da aceleração da obsolescência programada dos materiais. De forma geral, o capitalismo estético produz indivíduos transestéticos, que são "drogados" do consumo.

No contexto em que se inserem colocações teóricas sobre a cultura do consumo e a mercantilização ocasionada pela reprodutibilidade técnica da arte como processo da pós-modernidade, como indicado em Adorno e Horkheimer (1996), Benjamin (1987) e Bauman (2008), Lipovetsky (2015) indica a tese do "tempo de cérebro disponível" na hipermodernidade, quando uma moral coletiva está sendo construída pelas mídias. De acordo com os autores, "estamos no momento em que os sistemas de produção, de distribuição e de consumo são impregnados [...] por operações de natureza fundamentalmente estética. [...] É um modo de produção estético que define o capitalismo de hiperconsumo" (LIPOVETSKY, 2015, p. 13). Isso indica a necessidade de consumir para fins de prazer, desejo, sensação, emoção ou, simplesmente, pela condição inerente ao estabelecimento de um status social numa sociedade regada por representações de identidades moralmente ligadas ao poder de compra.

A estetização do mundo organiza-se em quatro eras que podem ser definidas a partir das relações que travam consenso com a vida cotidiana das pessoas no contexto econômico e cultural em que vivem: a artealização ritual, a estetização aristocrática, a moderna estetização do mundo e a era transestética.

Os sistemas, processos, narrativas e sentidos colocam-se na posição de transmutação, reconfiguração, ressignificação dos símbolos e códigos que permeiam as categorias anteriormente definidas. Na era do capitalismo artista, os sistemas não são individualizados, e os departamentos dos diversos setores da sociedade (arte, esporte e gastronomia, por exemplo) se misturam, congregando transnarrativas para realçar os desejos afetivamente associados aos produtos. Em outras palavras, o capitalismo artista é sistematizado, racional e operacionalizante.

Como características gerais, o capitalismo artista integra e generaliza a ordem do estilo, da sedução e da emoção nos bens destinados ao consumo mercantil (que é uma estratégia do encantamento) e também da dimensão empresarial das indústrias culturais e criativas, e desestabiliza as hierarquias artísticas e culturais e as demais esferas econômicas quando oportuniza o consumo desenfreado de produtos. As figuras desse enredo são a produção e a mercantilização de uma identidade artista, de um Homo aestheticus. Como consequência, decorre uma escalada do efêmero: sucessos musicais e cinematográficos momentâneos, fama e sucesso que se mantêm minimamente nas mídias etc. "A velocidade 
das tendências, das criações de todos os gêneros, da informação contínua é tal, que supera os limites da capacidade de assimilação do consumidor" (p. 56).

No capitalismo artista, os campos da produção econômica se hibridizam ferozmente. Artistas são empresários, e os empresários são considerados artistas. Os nomes dos ícones que representam a quebra de paradigmas nesse capitalismo são Andy Warhol (artista híbrido) e Steve Jobs (empresário artista). Ao contrário do que é defendido por Weber (2004), nesta etapa do capitalismo o espírito artista de encantamento está num "sistema diametralmente oposto, centrado na valorização das fruições materiais, no hedonismo do bem-estar, do divertimento e do lazer" (p. 125).

Em A estetização do mundo, enfatizando as discussões abordadas em outras oportunidades (LIPOVETSKY, 2009), as figuras inaugurais das vitrines e da alta-costura remodelam o capitalismo artista quando a visibilidade das vitrines e o desejo estacional da moda periódica regem as trocas comerciais da época. Outras figuras inaugurais do capitalismo artista são o design, o cinema, a música e a publicidade.

Além disso, atualmente a cidade ocupa a posição de um espaço transestético (p. 341) porque utiliza os elementos inaugurais do capitalismo artista: cidade-museu, turismo arquitetônico, estética ambiental, design futurista e cidades fechadas são alguns exemplos possíveis. Desse contexto surgem questões sobre como as relações sociais são definidas e reconfiguradas pela intervenção da beleza no mundo através do capitalismo artista.

Assim, A Estetização do Mundo é obra que discute, nas dimensões culturais, simbólicas, econômicas e ideológicas, o capitalismo na era da hipermodernidade. Nesse cenário, os setores estão interligados, conversam entre si e se hibridizam para fins de consumo. Aqui, a estética está presente nas formas e nos conteúdos dos produtos, e reflete a construção de uma efêmera ética mundial de consumo, assim como os objetos estetizados. Por isso, pergunta-se: pode a beleza salvar o mundo?

Wendell Marcel Alves da Costa é mestrando em Antropologia Social no Programa de Pós-Graduação em Antropologia Social da Universidade Federal do Rio Grande do Norte e Cientista Social pela UFRN.

marcell.wendell@hotmail.com

\section{Referências}

ADORNO, T. W. HORKHEIMER, M. Dialética do Esclarecimento. Rio de Janeiro: Zahar Editor, 1996. BAUMAN, Z. Vida para consumo: a transformação das pessoas em mercadorias. Rio de Janeiro: Jorge Zahar Ed., 2008. 
BENJAMIN, W. A obra de arte na época de sua reprodutibilidade técnica. In: Magia e técnica, arte e política. Ensaios sobre literatura e história da cultura. São Paulo: Editora Brasiliense, 1987, pp. 165-196.

LIPOVETSKY, G. O império do efêmero: a moda e o seu destino nas sociedades modernas. Tradução de Maria Lucia Machado. São Paulo: Companhia das Letras, 2009.

WEBER, M. A ética protestante e o “espírito" do capitalismo. São Paulo: Companhia das Letras, 2004. 